\title{
PRÁTICAS DE ENSINO PARA A INCLUSÃO DE UM ALUNO AUTISTA NAS AULAS DE MATEMÁTICA
}

\section{TEACHING PRACTICES FOR THE INCLUSION OF AN AUTISTIC STUDENT IN MATHEMATICS CLASSES}

\author{
Roberta Caetano Fleira ${ }^{1}$ \\ Solange Hassan Ahmad Ali Fernandes ${ }^{2}$
}

\begin{abstract}
Resumo: Este trabalho apresenta resultados de uma pesquisa que teve como objetivo analisar as práticas matemáticas de um aluno de catorze anos de idade, com necessidades especiais decorrentes do Transtorno do Espectro Autista (TEA), incluído em uma sala de aula regular de $9^{\circ}$ ano. Neste texto, são trazidas reflexões sobre o autismo, algumas considerações teóricas que dão suporte ao estudo e são descritos os procedimentos metodológicos empregados em sete sessões individuais e observações realizadas pela professora e pesquisadora nas aulas de Matemática, nas quais se discutiu o conceito matemático: fatoração de trinômios do segundo grau. No entanto, seguindo as orientações do material didático (apostila), foi necessário trabalhar primeiramente os conceitos de potenciação, radiciação e produtos notáveis. As análises destacam a importância e a influência dos instrumentos mediadores (materiais e semióticos) nas práticas matemáticas do aluno.
\end{abstract}

Palavras-chave: Autismo; Inclusão; Mediação; Práticas Matemáticas.

\begin{abstract}
The project demonstrates the result of a research which had the aim to analyze the practice of mathematic of a student at 14 years old, with special necessities due to the Autism Spectrum Disorder (ASD), included in a ninth grade regular classroom. On this text, reflections about autism, some theoretical considerations that give support to the study and the methodological procedures applied in seven individual sections and the observations done by the teacher and researcher at the mathematics classes, to work the mathematical concept: : factorization of second degree trinomials. However, following the guidelines of the didactic material (apostille), it was necessary to work first on the potentiation concepts, association and remarkable products. The analyzes highlight the importance and the influence of the mediating instruments (materials and semiotics) in the student's mathematical practices and for their effective inclusion in Mathematics classes.
\end{abstract}

Keywords: Autism; Inclusion; Mediation; Mathematical Practices.

\section{Introdução}

Neste artigo, são apresentados alguns resultados oriundos de uma pesquisa, na qual consideramos as práticas Matemáticas de um jovem estudante, com 14 anos de idade, que denominamos Caio. Matriculado no $9^{\circ}$ ano do Ensino Fundamental, de uma escola

\footnotetext{
${ }^{1}$ Mestrado em Educação Matemática pela Universidade Bandeirantes de São Paulo (UNIBAN). Universidade Anhanguera de São Paulo, São Paulo, São Paulo, Brasil. E-mail: robertafleira@ hotmail.com ${ }^{2}$ Doutorado em Educação Matemática pela Pontifícia Universidade Católica de São Paulo (PUC). Professora da Universidade Anhanguera de São Paulo, São Paulo, São Paulo, Brasil. E-mail: solangehf@gmail.com
} 
particular da cidade de Guarulhos, estado de São Paulo, Caio tem Transtorno do Espectro do Autismo (TEA).

Os episódios relatados, neste texto, são provenientes de uma sequência de intervenções realizadas com Caio, no contraturno e nas aulas de Matemática. Nosso propósito é desencadear reflexões acerca do Autismo e da importância da interação social no processo de aprendizagem. Para tanto, apresentamos as discussões relacionadas a uma proposta que envolveu a utilização de diferentes recursos pedagógicos no processo de ensino da fatoração de trinômios do segundo grau. Uma de nossas intenções, na pesquisa que desenvolvemos, era fazer com que Caio fosse incluído de fato nas aulas de matemática e, para isso, decidimos trabalhar com o aluno os mesmos conteúdos estudados em sala de aula, de maneira que ele pudesse acompanhar a turma.

Inicialmente, apresentamos algumas reflexões sobre Autismo e, em seguida, tratamos de reflexões teóricas, centradas nos trabalhos de Vygotsky, relacionados ao conceito de mediação. Essas reflexões ofereceram suporte para a elaboração, aplicação e análise de um conjunto de procedimentos metodológicos.

\section{Algumas reflexões sobre Autismo}

O autismo tem sido objeto de muitos pesquisadores em várias áreas do conhecimento e, talvez, esta seja uma explicação para as definições com diferentes abordagens que encontramos na literatura. Oliver Sacks considera que existam diferentes níveis de autismos e afirma que o autista que tem consciência de si mesmo pode desenvolver habilidades sociais e intelectuais, desenvolver a comunicação e a linguagem, tornando-se autônomo (SACKS, 2006).

Segundo Sacks (2006), cada autista é diferente do outro em suas características e comportamentos e, com o passar dos anos, a própria pessoa vai aprendendo consigo mesmo a conviver socialmente. Estudos apontam que o quanto antes houver o diagnóstico, mais rápido iniciam-se as ações para o desenvolvimento do indivíduo, o que amplia suas possibilidades de avanços. As abordagens possíveis são inúmeras, baseadas em atividades sensoriais, terapias, mudança de hábitos e inclusão escolar.

Bosa e Camargo (2008) acreditam que a convivência de crianças autistas com outras de mesma faixa etária, incluídas em uma sala de aula de ensino regular, seja uma solução para evitar a condição de viver isolada. As autoras apontam a escola como palco para ajudar no desenvolvimento dessas e de outras crianças que aprenderão a conviver e 
trabalhar com as diferenças. As crianças com o espectro autista apresentam a dificuldade de interação social como uma das principais características. Segundo Bosa (2006), devese apostar na convivência dessa criança com outras de mesma idade em uma escola regular, como uma forma de amenizar o isolamento autístico, respeitando e considerando a identidade e as características individuais da criança. O contato com outras crianças, que apresentam características e comportamentos diferentes, realiza um processo enriquecedor na aprendizagem e nas trocas de experiências, no qual todos os envolvidos aprendem com as experiências e se desenvolvem.

Dentro desse contexto, surgiram as teorias do desenvolvimento social, como a vygotskyana que afirmam a essencialidade da interação social para a construção e o desenvolvimento do ser humano. Alguns termos foram agregados a essa linha de estudo, entre eles competência social e habilidade social, que alguns autores consideram ter o mesmo significado. Para Camargo e Bosa (2008), a competência social consiste em utilizar alguma prática que foi aprendida por meio da relação com o outro, e que pode ser modificada e desenvolvida de acordo com a situação que o sujeito esteja vivenciando. Como mencionado, a escola foi apontada, pelas autoras, como o melhor ambiente para trabalhar e aprender a lidar com as diferenças, proporcionando o desenvolvimento da competência social, desde que seja um ambiente preparado, organizado e estruturado fisicamente e profissionalmente.

O ambiente escolar deve ser preparado para receber a diversidade. Por essa perspectiva, ele deve estar organizado para permitir que o aluno autista possa participar efetivamente. Desse modo, professores e profissionais envolvidos no processo de ensino devem preparar atividades que sejam previsíveis, uma vez que o fator surpresa não é um agente colaborador para alunos com Transtorno do Espectro autista (TEA), e todas as informações e instruções devem ser comunicadas em um tom de voz suave e normal. Deve-se evitar barulho e principalmente incentivar e encorajar a participação (SMITH, 2008).

No Brasil, a primeira associação de autistas foi a Associação dos Amigos Autistas (AMA), fundada na cidade de São Paulo no ano de 1983 por pais de autistas, quando o autismo era um transtorno pouco conhecido. A AMA não possui fins lucrativos e conta com o apoio da Secretaria de Estado de Educação e da Secretaria da Saúde. O objetivo é favorecer o autista com ações que impliquem no desenvolvimento social e, consequentemente, em uma vida melhor, de modo a fornecer aos familiares de autistas estratégias para o convívio social e familiar. De modo geral, as práticas pedagógicas 
utilizam a aplicação dos métodos como o TEACCH, PECS $^{2}$ (Picture Exchange Communication System) e $\mathrm{ABA}^{3}$ (Applied Behavior Analysis), pois, segundo a AMA, tratam-se de métodos muito conhecidos e que tiveram sua eficácia comprovada.

O Ministério da Educação (MEC), por intermédio da Secretaria da Educação Especial, elaborou trabalhos que podem servir para consulta e direcionamento de professores que trabalham com alunos de inclusão. Em 2003, foi lançado o guia "Saberes e práticas da inclusão - Dificuldades de aprendizagem - Autismo”. O documento garante que a inclusão do aluno com necessidades especiais decorrentes da síndrome do autismo na escola regular deve ser estruturada com salas de apoio e profissionais especializados, que sejam capacitados e saibam avaliar de maneira correta a especificidade do problema do aluno, para que as ações sejam traçadas com o cuidado e realizadas as adaptações necessárias para inserir o aluno em uma sala. O currículo pode ser o mesmo, porém, ele deve ser adaptado e embasado por atividades que facilitem e promovam a participação e a interação do aluno.

A diversidade e a personalização são elementos fundamentais no sistema educacional para que ocorra a educação de alunos com Autismo. Ao seguir um padrão de atendimento, as características peculiares de cada uma das pessoas com TEA não serão contempladas, pois não é possível traçar um mesmo método de aprendizagem para todos os autistas. É essencial a avaliação específica de cada caso, para que sejam indicadas as ações mais adequadas e possíveis para cada caso (COLL; MARCHESI; PALÁCIO, 2004).

Diante das considerações até aqui expostas, neste artigo, identificaremos algumas práticas de ensino adequadas para um adolescente, pertencente ao público alvo da educação especial com Transtorno do Espectro Autista (TEA), aprender conceitos matemáticos e aplicá-los. Essas atividades propostas nas aulas de matemática foram pensadas considerando suas peculiaridades.

\footnotetext{
${ }^{2}$ É um método de comunicação alternativa através de troca de figuras, é uma ferramenta valiosa tanto na vida das pessoas com autismo que não desenvolvem a linguagem falada quanto na vida daquelas que apresentam dificuldades ou limitações na fala.

${ }^{3}$ Análise comportamental aplicada que se embasa na aplicação dos princípios fundamentais da teoria do aprendizado baseado no condicionamento operante e reforçadores para incrementar comportamentos socialmente significativos, reduzir comportamentos indesejáveis e desenvolver habilidades. Há várias técnicas e aplicada que tem se mostrado útil no contexto da intervenção incluindo (a) tentativas discretas, (b) análise de tarefas, (d) ensino incidental, (e) análise funcional estratégias de ensino e tratamento comportamentais associados a análise do comportamento. Disponível em: www.ama.org.br - Acesso em: 10 de Junho 2014.
} 


\section{Algumas reflexões teóricas}

Vygotsky, em seus primeiros escritos na área da Defectologia, enfatizou a importância da educação social de crianças com qualquer tipo de deficiência e o potencial dessas crianças para um desenvolvimento normal (VALSINER; VEER, 1996).

Para Vygotsky, as crianças com limitações só teriam uma vida adequada se fossem educadas socialmente com alicerce na compensação ${ }^{4}$ dos problemas físicos, o que o levou a defender uma escola que integrasse essas crianças na sociedade, incentivando-as a tornarem-se trabalhadores socialmente valorizados (VALSINER; VEER, 1996). Nesse contexto, segundo Valsiner e Veer (1996), surgiu a primeira formulação do conceito de mediação e, dentro da perspectiva de Vygotsky, alguns elementos, definidos como instrumentos ${ }^{5}$ e signos $^{6}$, podem ser indicados como mediadores, tornando-se um meio nas relações mediadas (OLIVEIRA, 2009).

O uso de instrumentos e signos compartilha algumas propriedades importantes; os instrumentos são elementos externos voltados ao domínio da natureza e os signos, como são orientados internamente, dirigem a influência psicológica para o domínio do próprio indivíduo e são também chamados "instrumentos psicológicos", elementos orientados para o próprio indivíduo e auxiliam nos processos psicológicos, ou seja, nas tarefas que exigem memória ou atenção. Nesse sentido, os signos são elementos de representação da realidade (OLIVEIRA, 2002, p. 30).

As ações psicológicas superiores são mediadas por instrumentos e signos. Uma pessoa opera com esses dois elementos de maneira distinta nas diferentes fases de sua vida e os processos de mediação constroem-se e transformam-se ao longo do desenvolvimento, de maneira única em cada ser, constituindo o aprimoramento das funções psicológicas.

\footnotetext{
${ }^{4} \mathrm{O}$ termo compensação é bastante complexo, hoje temos, no Brasil, pesquisas científicas que contribuem para nossas reflexões. Dentre elas: a) DAINÊZ, Débora. Constituição humana, deficiência e educação: problematizando o conceito de compensação na perspectiva histórico-cultural. 2012. 119 p. Qualifying Project (Doctorate in Education) - Universidade Estadual de Campinas, Campinas, SP, 2012. b) DAINÊZ, Débora; SMOLKA, Ana Luiza B. O conceito de compensação no diálogo de Vigotski com Adler: desenvolvimento humano, educação e deficiência. Educação e Pesquisa, São Paulo, v. 40, n.4, p. 1093 1108, out./dez. 2014. c) CENCI, A. A retomada da defectologia na compreensão da teoria histórico-cultural de Vigostki. Anped, 2015.

5“Instrumento é um elemento interposto entre o trabalhador e o seu objeto de trabalho" (OLIVEIRA, 2009, p.26). Ex. a calculadora.

6"Signos são ferramentas que auxiliam nos processos psicológicos e não nas ações concretas" (OLIVEIRA, 2009, p.30).
} 
A linguagem é elemento fundamental nesse contexto, pois fornece formas de organização do real que constituem a mediação entre o sujeito e o objeto de conhecimento. A compreensão das relações entre o pensamento e a linguagem é essencial para o entendimento do funcionamento psicológico do ser humano (VYGOTSKY, 1998).

$\mathrm{Na}$ pesquisa que desenvolvemos, orientadas pela perspectiva vygotskyana, partimos da hipótese de que Caio, um aluno com TEA, tem o mesmo potencial que seus colegas para a aprendizagem de conteúdos matemáticos. Considerando as particularidades de Caio, todas as ações que conduzimos nas interações instrucionais, tinham o propósito de viabilizar o acesso a objetos matemáticos e despertar o interesse do aluno que, muitas vezes, ficava disperso. Desse modo, mudamos a prática ensino, escolhemos técnicas que considerávamos adequadas para Caio e disponibilizamos nos cenários de aprendizagem ferramentas que poderiam favorecer a emergência de estratégias para a realização das tarefas.

Segundo Oliveira (2009), a mediação é um processo essencial para tornar possíveis atividades psicológicas voluntárias, intencionais, controladas pelo próprio indivíduo. Na visão de Vygotsky, a relação do homem com o mundo, ao longo do desenvolvimento do indivíduo, é predominantemente mediada por elementos, e as relações mediadas predominavam sobre as relações diretas. Assim, neste artigo, consideraremos o construto da Mediação para a análise dos episódios que envolvem o aluno com autismo, fazendo a Fatoração de Trinômios do segundo grau e desenvolvendo outros conceitos matemáticos.

Diante da perspectiva vygotskyana, acreditamos que, durante as atividades realizadas, a mediação se deu por meio dos materiais utilizados e das intervenções da professora/pesquisadora. Tais ocorrências transformaram a trajetória de aprendizagem e a convivência social do sujeito da pesquisa.

\section{0 estudo}

No estudo que desenvolvemos, buscamos analisar as práticas de um aluno de 14 anos de idade, com necessidades especiais decorrentes da síndrome do autismo que, como foi dito, neste texto será chamado Caio. Segundo a mãe dele, até os quatro anos de idade o garoto não apresentava comunicação verbal, motivo que a levou a desconfiar de que o problema dele fosse surdez. Após o período de um ano e tendo passado por vários especialistas, ele recebeu o diagnóstico de autismo. 
O aluno, desde os cinco anos, foi incluído em sala de aula regular, em colégios particulares e com alunos da mesma faixa etária. Atualmente, ele está matriculado no $9^{\circ}$ ano de uma escola regular que utiliza um sistema de ensino apostilado. Ele é alfabetizado, apresenta comunicação verbal, compreensão em relação ao que é solicitado, possui afinidade com equipamentos tecnológicos, enorme encantamento e domínio para lidar com equipamentos eletrônicos, tais como tablet, aparelho celular, calculadora e computador. Em relação à Matemática, a pesquisadora, que também é sua professora desde o $8^{\circ}$ ano, pôde perceber que Caio não conhecia os algoritmos da matemática para efetuar cálculos, não participava das aulas, faltava muito e simplesmente ficava sentado com a apostila em branco e copiava o conteúdo quando queria. Os professores que lecionavam aulas para o aluno elaboravam avaliações com o conteúdo de $4^{\circ}$ ano. Não era permitido o uso de calculadora e nem que ele fizesse a prova na sala de aula, junto com os seus colegas.

$\mathrm{Na}$ tentativa de promover o desenvolvimento do aluno para que ele pudesse participar ativamente das aulas de matemática, realizando tarefas adequadas à série em que se encontrava e para que ele realizasse as avaliações junto com a turma, iniciamos sessões de atendimento individual, no contraturno das aulas. Para isso, elaboramos atividades nas quais criamos situações de aprendizagem de acordo com o tema que estava sendo trabalhado em classe.

Neste artigo, apresentamos um episódio no qual o conceito central a ser desenvolvido era a fatoração de trinômios do segundo grau; no entanto, seguindo as orientações do material didático (apostila), foi necessário trabalhar primeiramente o conceito de potenciação e de radiciação. Nas intervenções apresentadas neste texto, foram utilizadas as seguintes ferramentas: calculadora (Figura 1 e 2), material dourado (Figura 3), caixa dos produtos notáveis (Figura 4) e a Tabela do Produto (Figura 10).

Foram realizadas sete sessões de aproximadamente cinquenta minutos cada, que foram vídeo-gravadas e dividiram-se da seguinte maneira: sessões um e dois potenciação e radiciação com o uso da calculadora; sessão três - potenciação com uso do material dourado; sessões quatro e cinco - produtos notáveis e sessões seis e sete fatoração do trinômio do segundo grau com o auxílio da Tabela do Produto. Destacamos que a professora de matemática de Caio é uma das pesquisadoras que conduziu o estudo. 


\subsection{Potenciação e Radiciação na calculadora}

O primeiro encontro foi difícil, pois o aluno ofereceu certa resistência para sair de sua rotina e frequentar a escola no contraturno. Era muito pouco atraente frequentar aulas de Matemática, disciplina que Caio não demonstrava interesse e na qual tinha dificuldades de concentração.

Havíamos percebido que Caio não dominava os algoritmos das quatro operações fundamentais e não sabia tabuada de cor. Assim, decidimos que iriamos introduzir o uso da calculadora. Para nós, não fazia sentido, naquele momento, trabalhar com as quatro operações fundamentais e seus algoritmos, uma vez que todo o desenvolvimento dos processos faria com que Caio ficasse mais tempo "excluído" durante suas aulas regulares de matemática.

Ao saber que iria poder usar a calculadora para fazer os cálculos nas atividades extraclasse e, a partir daquele dia, também em sala, Caio apresentou entusiasmo, principalmente por ser apaixonado por tecnologia. Cada tecla da calculadora que lhe foi apresentada foi utilizada, sem dificuldade alguma, mas sua preocupação era o fato de que na escola era proibido usar calculadora.

Iniciamos com os conceitos de potenciação e de raiz quadrada que eram propostos no material didático de Caio. O primeiro passo foi verificar se o aluno sabia identificar os símbolos de potências e raízes. Oralmente, ele reconheceu cada uma das situações propostas, dizendo que já havia aprendido em sala e pôde ler dois à terceira, três à quinta, raiz quadrada de nove, raiz cúbica de nove, mas não tinha a menor ideia do que significava ou como calcular.

A partir do momento que Caio recebeu atenciosamente a explicação da pesquisadora e entendeu o que deveria fazer para calcular potências de diversas bases e raiz quadrada, não ouviu mais nada e começou a executar os cálculos na calculadora.

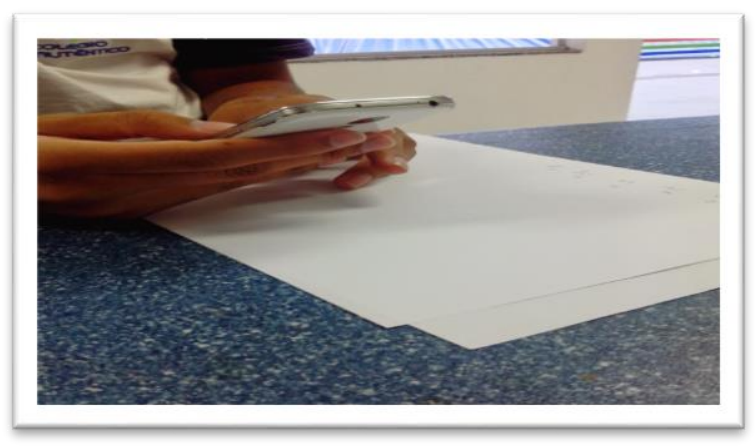

Figura 1: Potência e calculadora Fonte: Arquivo do grupo

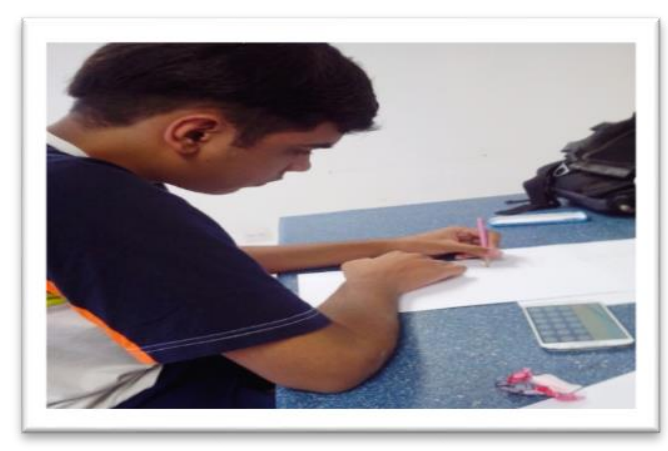

Figura 2: Raízes

Fonte: Arquivo o grupo 
No segundo encontro, o aluno fez os cálculos sozinho e não prestou atenção à explicação da pesquisadora que tentou iniciar as atividades retomando o que foi discutido no encontro anterior. Na sala de aula, a professora pesquisadora autorizou que Caio usasse a calculadora, que ele imediatamente pegou e passou a usá-la "escondido", pois não queria que os amigos o vissem usando a máquina. Com a calculadora escondida, ele começou a responder os exercícios da apostila, ação totalmente nova de Caio em sala de aula, que antes somente copiava quando tinha vontade. Durante as aulas de matemática, o aluno jamais havia tentado resolver um exercício. Ao resolver o primeiro exercício em sala, resolução da potência $7^{3}$, ele chamou a professora para perguntar se estava correto e após escutar a resposta afirmativa, vibrou e disse que nunca pensou que "um dia iria resolver algum negócio da apostila".

\subsection{Potenciação com o material dourado}

No terceiro encontro, o aluno chegou animado com a calculadora e quando percebeu que as potências seriam resolvidas usando um material diferente, se desinteressou e ficou com o olhar distante. Nessa atividade, optamos pelo uso do material dourado para o cálculo de algumas potências, uma vez que, constatada a dificuldade de caio com os algoritmos, pretendíamos explorar as representações geométricas dos conceitos matemáticos que iriamos estudar.

Ao utilizarmos o material dourado para representar dois ao quadrado (Figura 3), criou-se um impasse. Como o material é composto por bloquinhos, Caio logo foi dizendo que aquela representação era dois ao cubo, pois era composto por cubos. Três ao quadrado, ele entendeu como três ao cubo, pois era composto por cubos que tem três "lados"; quatro ao quadrado para ele era quatro ao cubo, pela mesma justificativa. Só se convenceu de que algo não estava certo quando contou o número de bloquinhos e verificou que era o mesmo valor que encontrava quando fazia a potência com a calculadora. Entusiasmou-se e disse que só confiava na calculadora, e que se era mais fácil, não havia necessidade de querer aprender de outra maneira, rejeitando o uso do material, mas compreendeu que as potências que encontrava eram do tipo $a \cdot a=a^{2}$. 


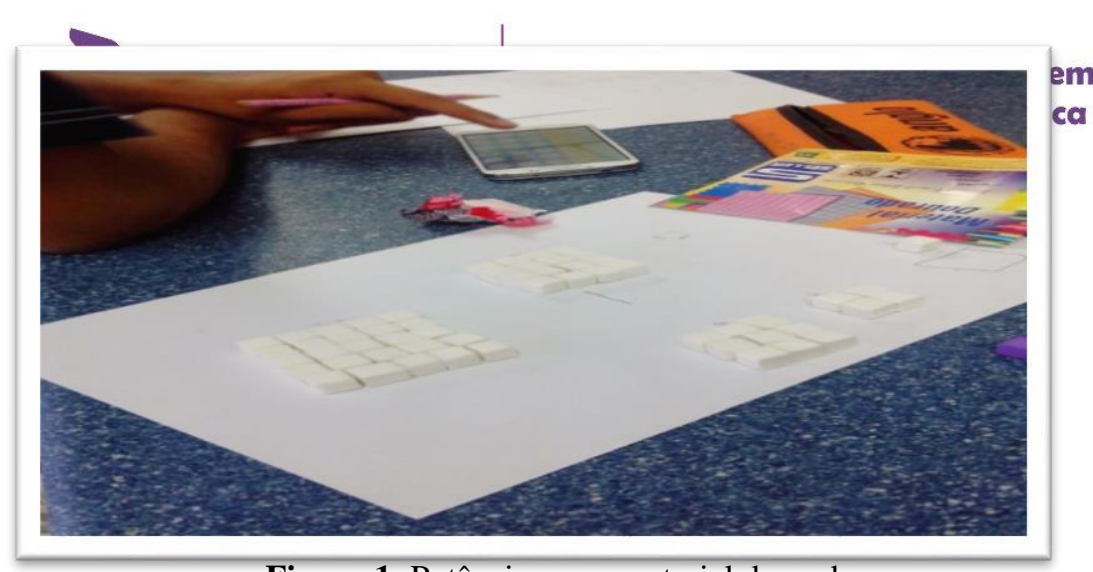

Figura 1: Potências com material dourado

Fonte: Arquivo do grupo de pesquisa

A partir dessa sessão, o aluno começou a acompanhar e a participar das aulas de matemática no horário regular. Já realizava as contas com a calculadora sem esconder dos colegas e começou a perceber que eles estavam reconhecendo as mudanças de seu comportamento. As sessões no contraturno passaram a fazer parte da sua rotina e ele mesmo já confirmava os encontros mostrando ansiedade.

\subsection{Produtos notáveis}

No quarto e no quinto encontros, trabalhamos com o conceito de produtos notáveis usando o material confeccionado por Lúcia Virgínia Mamcasz Viginheski (Figura 4). O aluno gostou muito e se encantou pelo material colorido, feito em madeira, com diferentes texturas e fácil de manusear. A pesquisadora percebeu que com o auxílio do material, Caio acabou esquecendo um pouco a calculadora.

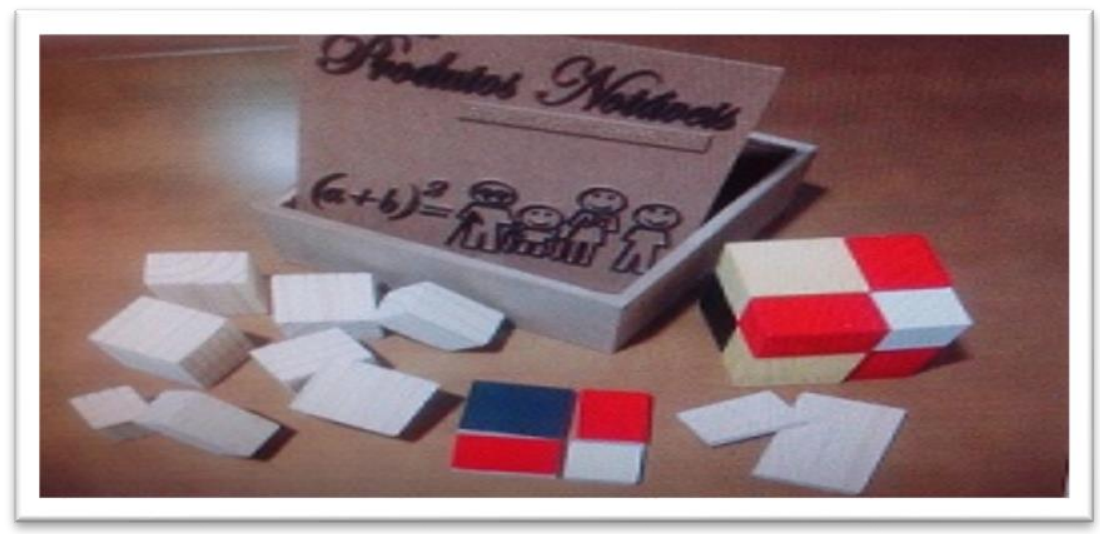

Figura 4: Caixa dos produtos notáveis Fonte: Arquivo do grupo de pesquisa

A proposta da apostila era retomar os conceitos de produtos notáveis e de fatoração para aplicá-los à resolução das equações do segundo grau (Figura 5). 


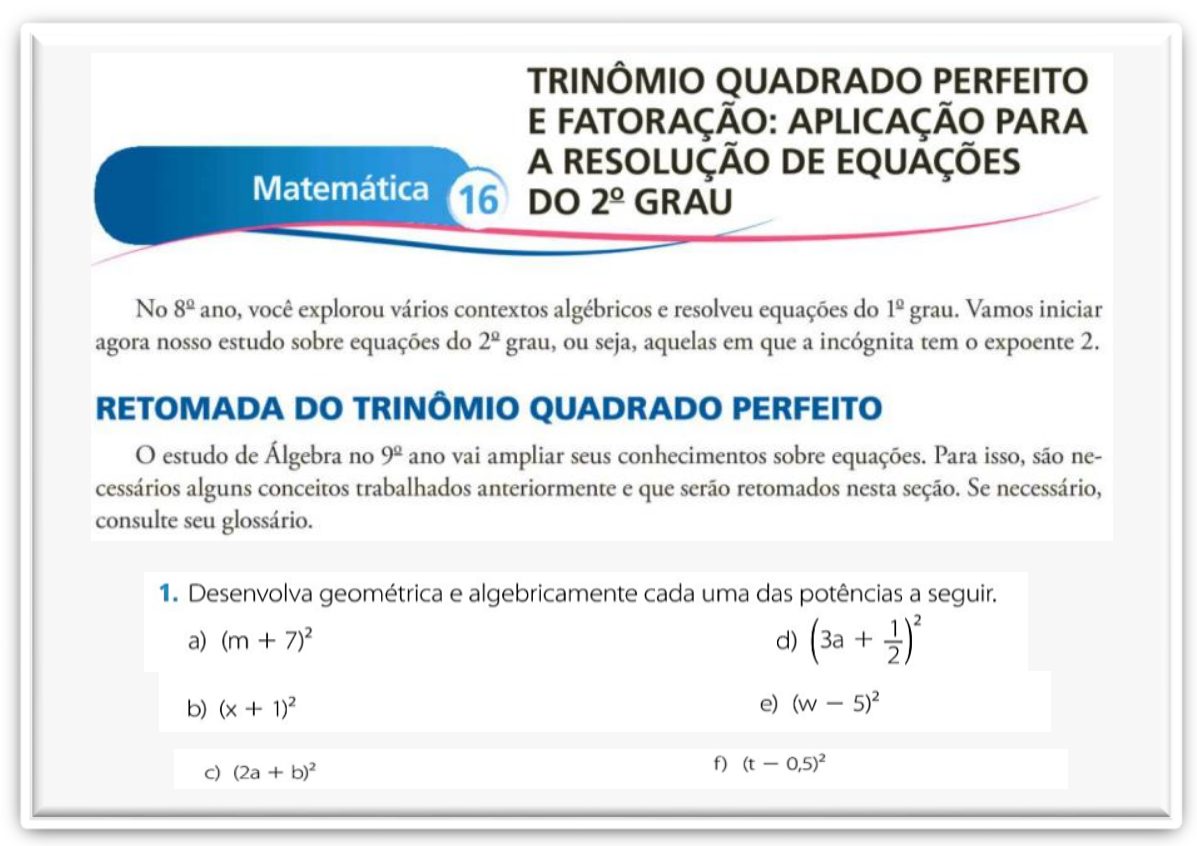

Figura 5:Conteúdo da apostila

Fonte: material da pesquisa

A proposta contida na apostila envolvia a representação geométrica do quadrado da soma de dois termos, ou seja, da área do quadrado cujos lados correspondem à soma de dois termos. Por exemplo, ao representar geometricamente a potência $(m+n)^{2}=m^{2}+$ $2 m n+n^{2}$ (Figura 6), teríamos:
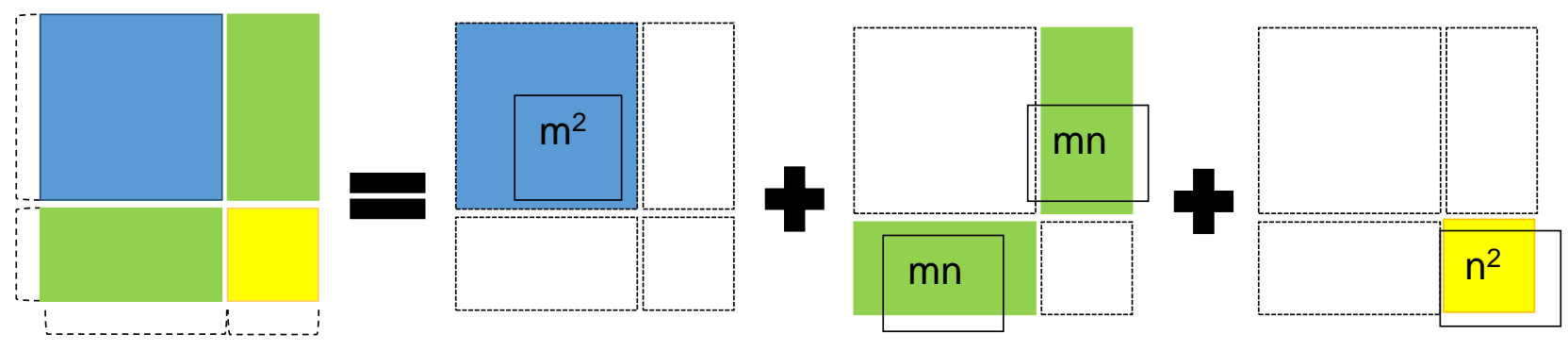

$\mathrm{m}$

n

Figura 6: Representação geométrica do quadrado da soma de dois termos

Fonte: Elaborado pelas autoras

A caixa dos produtos notáveis (Figura 4) dava a Caio a liberdade de montar os quadrados e de pensar suas dimensões, mas rapidamente ele foi percebendo as regularidades das formas geométricas. Por exemplo, ele notou que para formar o quadrado maior (quadrado da soma dos dois termos), utilizando os dois menores que possuía (quadrado dos termos), eram necessários dois retângulos idênticos cujas dimensões eram os dois termos da soma. A pesquisadora explicou que a área dos dois 
retângulos era obtida por meio do produto dos seus lados. Ao receber as informações, rapidamente, Caio passou a realizar todos os exercícios perfeitamente e, gradativamente, abandonou o uso físico do material, mantendo o esboço da representação geométrica no caderno.

O aluno não teve dificuldade para executar exercícios com letras e números, tais como $(x+2)^{2}$ ou $(a+b)^{2}$. A estratégia associada à representação geométrica dos Produtos Notáveis foi bem compreendida pelo aluno. Caio quis mostrar o material, para os colegas de classe e pediu para a pesquisadora/professora o levar para a aula.

Vale ressaltar que, para iniciar as atividades, Caio aguarda que lhe fossem dados os comandos, caso contrário ele não começava. Depois que entendia o processo que lhe permitiria realizar a atividade, ele não escutava mais nada e ia executando (Figura 7). Ele não conversava ou fazia questionamentos, só respondia o que lhe era perguntado, e quando tinha alguma dúvida ou quando precisava que fosse dado algum comando para a realização da atividade, buscava rapidamente os olhos da pesquisadora.

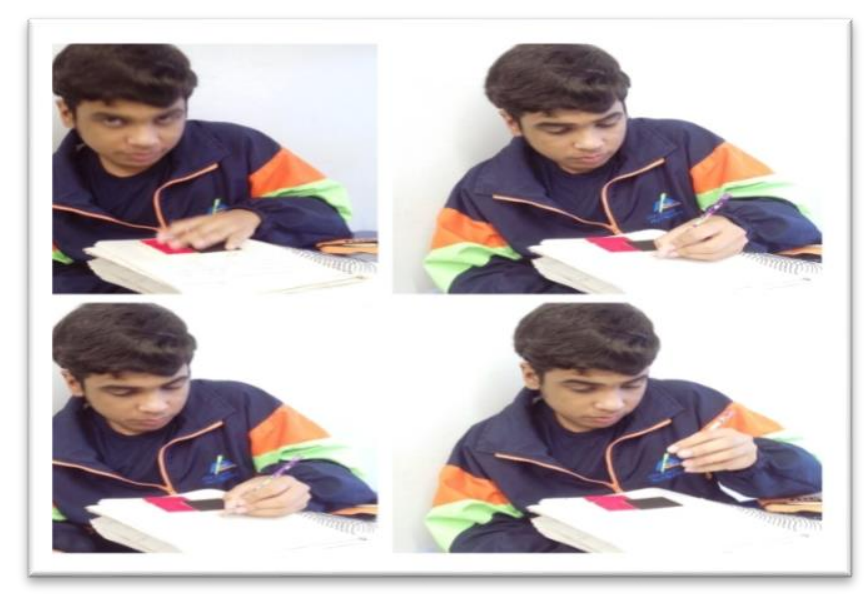

Figura 7: Caio usando a Caixa dos produtos notáveis Fonte: Arquivo do grupo de pesquisa

Caio participou ativamente das aulas de matemática com os colegas, e o próximo passo seria a fatoração de um trinômio do segundo grau, mais especificamente fatoração de trinômio quadrado perfeito.

\subsection{Fatoração com o auxílio da Tabela do Produto}

Conforme mencionado anteriormente, nosso objetivo, neste artigo, é desencadear reflexões acerca da importância da interação e da mediação no processo de aprendizagem. 
Para tanto, buscamos meios para romper a barreira de comunicação e para que Caio pudesse acompanhar sua turma e conseguisse realizar com autonomia as atividades propostas nas aulas.

Planejamos duas sessões para o estudo da Fatoração do Trinômio quadrado perfeito. A atividade seguinte consistia no caminho inverso, ou seja, determinar os lados do quadrado que representa uma determinada área (o trinômio) (Figura 8).

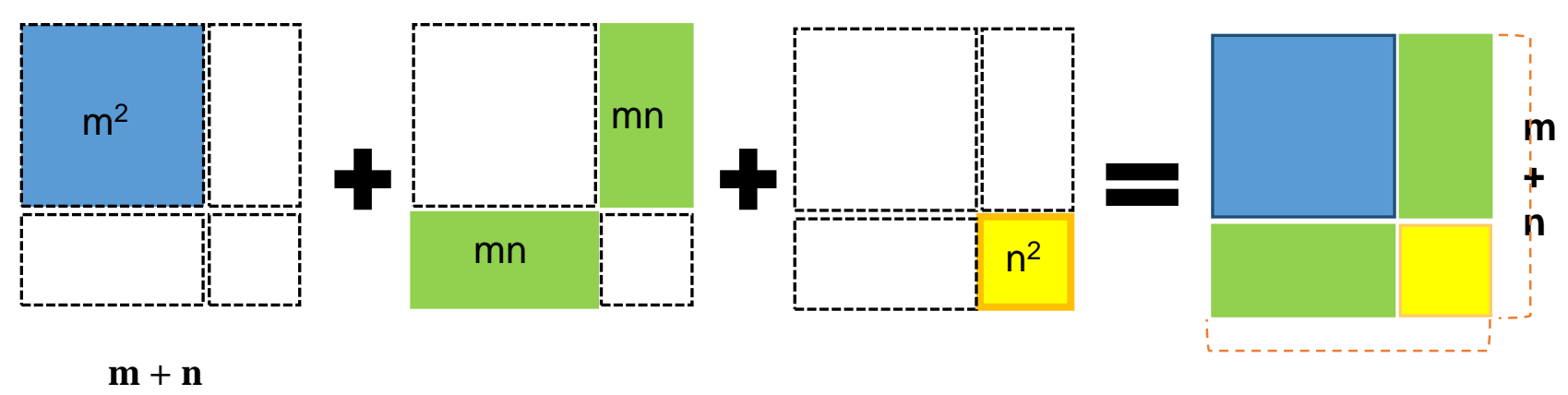

Figura 8: Representação geométrica de um trinômio quadrado perfeito Fonte: Elaborado pelas autoras

$\mathrm{Na}$ sala de aula, a professora observou Caio realizando a atividade da apostila (Figura 9). Ela notou que ele montava o quadrado cuja área representava o trinômio, mas para determinar o valor numérico que deveria ser adicionado a variável, ele usava o método das tentativas. Por exemplo, considerando o trinômio $x^{2}+12 x+36$, ao questionálo - “Quanto vale o lado de um quadrado de área 36?” Caio, usando a calculadora, iniciava um processo incansável fazendo multiplicações sucessivas de dois números quaisquer até obter produto 36. Tentava um vezes um, um vezes dois, três vezes cinco, cinco vezes cinco, aleatoriamente e, assim que conseguia o resultado pretendido, o aprendiz o aceitava como verdade absoluta, uma vez que havia sido obtido pela calculadora. 
2. Determine geometricamente a medida dos lados dos quadrados representados pelos trinômios. A seguir, escreva a expressão algébrica que representa essa medida, ou seja, fatore os trinômios quadrados perfeitos.
a) $x^{2}+12 x+36$
c) $4 p^{2}+4 p+1$

Lembre-se: cada um dos trinômios é denominado trinômio quadrado perfeito, pois representa a área de um quadrado. Esse quadrado é formado por dois quadrados diferentes e dois retângulos congruentes cujos lados diferentes têm as mesmas medidas dos lados dos quadrados.

b) $m^{2}-16 m+64$ d) $y^{2}-y+\frac{1}{4}$

Figura 9: Atividade da apostila

Fonte: Apostila do aluno

No atendimento individual, a princípio, a pesquisadora escolheu aleatoriamente o número 16 como resultado de todos os cálculos que Caio realizaria e pediu para que o aprendiz executasse, com o auxílio da calculadora, as operações: 32/2, 13+3, 10+6, 18-2, 8.2 e 4.4, para que ele percebesse que outros números somados, multiplicados, subtraídos ou divididos poderiam dar o mesmo resultado, fato que o aluno aceitou. Aqui, podemos perceber, de acordo com a teoria de Vygotsky, a importância da mediação. A pesquisadora com a fala e a calculadora foram elementos intermediários e essenciais nesse processo.

Diante desse contexto, planejamos as ações do nosso próximo atendimento individual. O nosso objetivo, era que Caio conseguisse visualizar na Tabela do Produto (Figura 10) os possíveis candidatos ao resultado pretendido, facilitando o procedimento para a fatoração do trinômio.

A Tabela do Produto, confeccionada em madeira revestida com uma manta metálica nas dimensões $30 \mathrm{~cm} \times 40 \mathrm{~cm}$, tem na primeira linha e coluna os números de $0 \mathrm{a}$ 12 e é preenchida com os respectivos produtos. Os resultados desejados são marcados com ímãs. Para que o aluno pudesse trabalhar, durante as aulas na classe, outra tabela nas dimensões $10 \mathrm{~cm} \times 15 \mathrm{~cm}$ foi produzida em papel. 

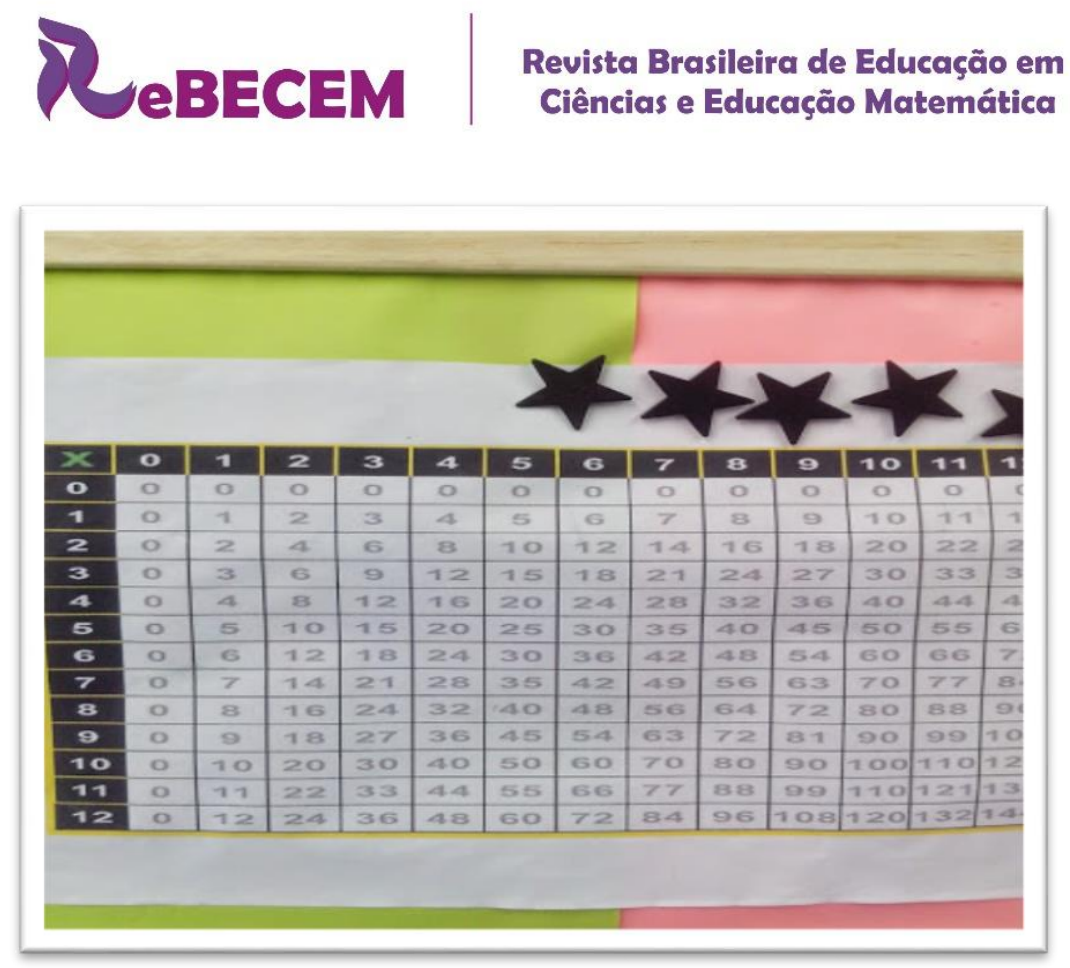

Figura 10:Tabela do Produto

Fonte: Arquivo do grupo de pesquisa

A pesquisadora apresentou a tabela ao aluno, explicando que os números destacados em preto na horizontal e na vertical eram os valores que seriam multiplicados e os demais números eram os resultados obtidos com as multiplicações. Iniciamos o procedimento do uso da tabela pedindo a Caio que escolhesse um número. Ele escolheu o número 4. A pesquisadora então solicitou que ele encontrasse todos os números 4 na parte branca da tabela e colocasse ímãs sobre eles, destacando que ele estaria encontrando os números que multiplicados tinham o número 4 como produto. $\mathrm{O}$ aluno encontrou três valores (Figura 11), -- 1 x 4, 4 × 1, 2 × 2 .

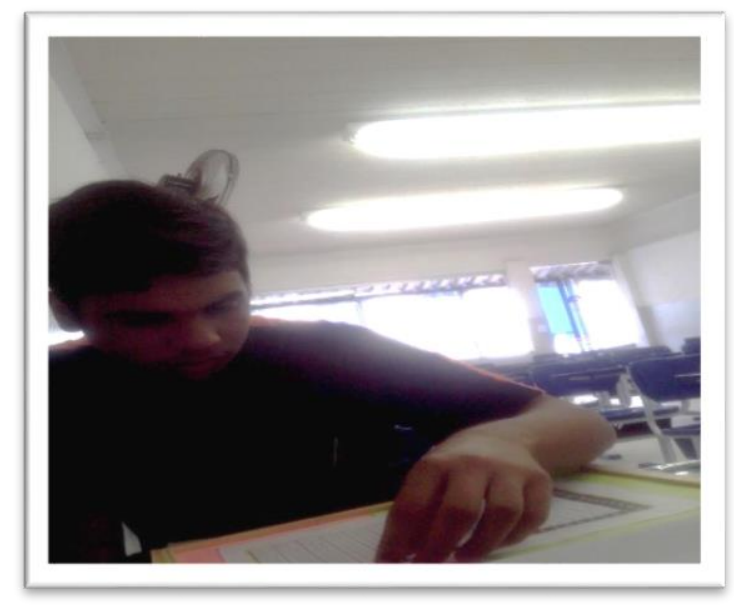

Figura 11: Caio utilizando a Tabela do Produto Fonte: Arquivo do grupo de pesquisa. 
Em seguida, a pesquisadora solicitou que o aluno verificasse se os resultados obtidos eram válidos, ou seja, se realmente tinham o 4 como resultado. Ele pegou a calculadora e conferiu cada uma das três multiplicações e confirmou que elas estavam corretas, ação que o fez acreditar que a tabela era composta por resultados corretos.

O próximo número escolhido por Caio foi 12. A pesquisadora solicitou ao aluno que destacasse na tabela as multiplicações que apresentavam o número doze como resultado.

Pesquisadora: Quando o doze tá aí, que número que você tem que multiplicar? Caio: Um e doze

Pesquisadora: Então anota aí. Agora qual outra possibilidade de dar doze? Na multiplicação.

Caio: É três e quatro. Vai dar doze?

Pesquisadora: Confere.

Conferiu na calculadora, percebeu que estava correto, anotou e seguiu olhando a tabela em busca de mais pares de números que apresentassem o 12 como resultado do produto de dois números.

Caio: Achei o 4 e 3. É a mesma coisa? Precisa colocar de novo?

Pesquisadora: Não tem necessidade. E tem outros?

Caio: 6 e 2.

Conferiu na calculadora e percebeu que dava certo.

Pesquisadora: Agora ao invés de ficarmos chutando os candidatos, ficará mais simples encontrá-los nessa tabela.

Caio percebeu que três vezes quatro tem produto doze, e o mesmo acontece com quatro vezes três. Que o mesmo acontece com seis vezes dois e dois vezes seis, ou seja, percebeu a propriedade comutativa na multiplicação. Com a calculadora ele não havia percebido a propriedade. A interferência da pesquisadora foi fundamental para retirar a calculadora e introduzir o outro instrumento material - a Tabela, mediando a situação.

Ao analisarmos a situação descrita anteriormente, percebemos que, ao trabalhamos com as Potências e as Raízes, a calculadora foi um excelente mediador. Quando passamos para a Fatoração dos Trinômios do $2^{\circ}$ grau, esse instrumento não cumpriu o papel esperado. Foi com o auxílio da tabela que o aprendiz visualizou que existia mais de uma possibilidade para o produto de dois números ser o mesmo valor numérico. Nessa ação, a interferência da pesquisadora foi fundamental.

No atendimento seguinte, Caio deixou de utilizar a calculadora. Contando com a Tabela Produto, iniciamos a resolução da fatoração de trinômios do $2^{\circ}$ grau com o trinômio $x^{2}+12 x+36$. A professora, já havia explorado o tema em sala, então só foi preciso 
um feedback para que ele conseguisse dizer que, primeiramente, seria preciso encontrar dois números que tivessem 12 como resultado da soma e 36 como solução do produto.

A pesquisadora solicitou que Caio destacasse, na Tabela do Produto, todos os produtos 36. O aluno seguiu com o procedimento encontrando os três possíveis candidatos, 3 × 12, 6 × 6 e 12 × 3. Em seguida, ela questionou - "Quais desses pares têm soma 12?" Após realizar as somas na calculadora, o aluno respondeu: 6 e 6 . O próximo passo consistiu em escrever a equação na forma fatorada com os valores obtidos $(x+6)$ $(x+6)=(x+6)^{2}$.

A pesquisadora solicitou a fatoração do trinômio $\mathrm{x}^{2}+5 \mathrm{x}+6$.

Pesquisadora: Primeiro você vai procurar na tabela o número que você quer. É quanto? Caio: Seis.

Pesquisadora: Isso, destaque aí na sua tabela o seis e me diga quais pares de números que possuem produto seis e soma 5.

Caio: um e seis, mas a soma é sete.

Pesquisadora: Então vê outro par.

Caio ficou pensativo por alguns instantes e, sem olhar a tabela respondeu.

Caio: três e dois.

Pesquisadora: E quanto é três mais dois?

Caio: Cinco, aí eu coloco xis mais três e xis mais dois.

Ao analisarmos essa ação de Caio ficar pensativo e conseguir responder sem o auxílio da tabela e, a partir daquele momento não a utilizar mais, percebemos que o instrumento material, como preconiza a teoria de Vygotsky, naquele momento, havia se transformado em um signo. Nessa linha de pensamento, Oliveira (2009) afirma que o signo age como um instrumento de atividade psicológica de maneira análoga ao papel de um instrumento de trabalho. A mediação semiótica - a fala da pesquisadora - foi fundamental na mediação com os instrumentos materiais, possibilitando a utilização da ferramenta psicológica pelo sujeito.

Observamos, durante o estudo, que Caio demostrava satisfação e segurança em executar os procedimentos de forma sistemática durante as aulas de Matemática. Nas aulas que trataram da fatoração de trinômios do $2^{\circ}$ grau com o método apresentado, $\mathrm{o}$ aluno participou pedindo para fazer correções na lousa e perguntando discretamente para a professora o que não compreendia bem. Caio fazia questão de ter a tabela e a calculadora sobre a mesa, mesmo que não as utilizasse na resolução dos exercícios propostos. A postura e as ações do aluno durante as aulas foi mudando. Caio esperava ansioso pelas aulas de Matemática e pelo dia do atendimento individual. 


\section{Considerações finais}

No período das sessões mencionadas neste artigo, algumas mudanças visíveis puderam ser percebidas no aluno com TEA. Ao perceber que podia acompanhar seus colegas em sala de aula, Caio desenvolveu autoestima, começou a se arrumar e a cuidar mais da aparência, a participar das aulas, a solicitar o auxílio mesmo que de forma discreta para a professora, a pedir para ir a lousa para resolver exercícios e, segundo sua mãe, ele passou a gostar de frequentar a escola no horário regular e no contraturno.

O trabalho com Caio se desenvolveu durante todo o ano letivo. Neste artigo, apresentamos algumas situações de ensino e de aprendizagem Matemática de Caio, no ambiente escolar, envolvendo Fatoração de Trinômios do Segundo Grau e outros conceitos matemáticos, com o intuito de avaliar o potencial de diferentes práticas e materiais - elementos mediadores - que permitiram o acesso do aprendiz a conteúdos matemáticos e contribuíram para que ele pudesse acompanhar as aulas de Matemática juntamente com seus pares.

As práticas adotadas, que neste caso centram-se nos instrumentos de mediação -os materiais e as intervenções da pesquisadora, despertaram o interesse de Caio e possibilitaram a emergência de suas habilidades que antes não eram percebidas. Como um "efeito colateral", Caio passou a ter um outro olhar para si mesmo, pois agora é respeitado pelos colegas; para a professora, que antes era praticamente invisível para ele; e para o ambiente escolar, o qual passou a gostar de frequentar.

O planejamento deste estudo partiu do princípio de que o aluno poderia desenvolver-se e avançar, para posteriormente tornar-se independente em suas práticas escolares. Traçamos ações que respeitaram as peculiaridades do aprendiz e que reconheciam a necessidade de traçar uma trajetória de aprendizagem adequada para ele. Não fazia sentido trabalhar conceitos básicos como os algoritmos das operações fundamentais com um aluno que demonstrava potencial para acompanhar seus colegas de turma. Cabe destacar que, provavelmente, Caio não tinha conhecimento de conceitos básicos de matemática escolar por não ter tido contato com eles. Em entrevista com sua mãe e seus professores, pudemos notar que Caio sempre foi incluído fisicamente na sala de aula. Infelizmente, ele ainda não havia vivido a oportunidade de estar de fato incluído na aula de matemática. 


\section{Revista Brasileira de Educação em \\ Ciências e Educação Matemática}

\section{Referências}

AMERICAN PSYCHIATRIC ASSOCIATINON (APA). Diagnostic and Statistical Manual

of Mental disorders - DSM-5. 5. ed. Washington: American Psychiatric Association, 2013.

ASPERGER, H. Autistic psychopathy in childhood. In: FRITH, U. (Ed.). Autism and Asperger syndrome. Londres: Cambridge University Press, 1991. p. 37-92.

ASSOCIAÇÃO DE AMIGOS AUTISTAS (AMA). Disponível em:

<http://www.ama.org.br/html/home.php>. Acesso em: 29 out. 2017.

AUTISM ASSOCIATION OF WESTERM AUSTRALIA. Disponível em:

<http://www.autism.org.au/what-is-autism/overview.aspx.> Acesso em: 29 out. 2017.

BOSA, C. Atenção compartilhada e identificação precoce do autismo. Psicologia, Reflexão e Crítica, Porto Alegre, v. 15, n. 1, p. 77-88, 2002. Disponível em:

<http://www.scielo.br/pdf/prc/v15n1/a10v15n1.pdf>. Acesso em: 29 out. 2017.

BOSA, C. A.; CAMARGO, S. P.H. Competência Social, Inclusão Escolar e Autismo: Revisão Crítica de Literatura. Psicologia \& Sociedade, Belo Horizonte, v. 21, n. 1, p. 65-74, jan./abr. 2008. Disponível em: <http://www.scielo.br/pdf/psoc/v21n1/08.pdf>Acesso em: 29 out. 2017.

COLL, C.; MARCHESI, A., PALÁCIO, J. (Org.). Desenvolvimento psicológico e educação. vol. 3. Porto Alegre: Artmed, 2004.

OLIVEIRA, M. K. de. Vygotsky: Aprendizado e desenvolvimento: um processo sóciohistórico. São Paulo: Scipione, 2009.

SACKS, O. Um antropólogo em Marte: sete histórias paradoxais. Tradução de: Bernardo Carvalho. 4. ed. São Paulo: Companhia das Letras, 2006.

SMITH, D. D. Introdução à Educação Especial: ensinar em tempos de inclusão. 5. ed. Porto Alegre: Artmed, 2008.

VEER, R.; van der; VALSINER, J. Vygotsky - Uma síntese. Tradução de: Cecília C. Bartalotti. 4. ed. São Paulo: Loyola, 1996.

VYGOTSKY, L. S. Obras escogidas V. Fundamentos da Defectología. Traducción: Julio Guillermo Blank. Madrid: Visor, 1997.

VYGOTSKY, L. S.A formação social da mente. Tradução de: José Cipolla Neto, Luís Silveira Menna Barreto, Solange Castro Afeche. 6. ed. São Paulo: Martins, 1998.

VIGINHESKI, L.V.M. Produtos Notáveis. Disponível em:< https://docs.google.com/file/d/0BxzURxVy6eSjZXdBM2VsYTZaRWc/edit>. Acesso em: 29 out. 2017.

Recebido em: 13 de novembro de 2017.

Aceito em: 09 de dezembro de 2017. 